\title{
Problem Analysis and Cracking Strategies for Artificial Intelligence Curriculum Education
}

\author{
Dan Zhou ${ }^{1, \mathrm{a}}$, Nana Yan ${ }^{2, \mathrm{~b}^{*}}$ \\ ${ }^{1}$ Tencent Research Institute, Beijing 100080, China \\ ${ }^{2}$ State Key Laboratory of Remote Sensing Science, Aerospace Information Research Institute, Chinese Academy of \\ Sciences, Beijing 100101, China \\ adennisdzhou@tencent.com \\ b*yannn@radi.ac.cn
}

\begin{abstract}
Artificial Intelligence Curriculum Education(AICE) in Elementary and Middle Schools has been carried out in many parts of the country, but it has also exposed several problems, such as lack of unified teaching guidance, weak teaching ability of some teachers, and educational resources imbalance. The article puts forward some solutions through on-site visits, symposium and other methods, combining with the current local policies and teaching practice, from the aspects of curriculum standard establishment, teachers' ability development, students' core qualities training, and educational resources equity according to local conditions. It is recommended to unify the cognition based on the new curriculum standard, enrich the teaching practice of hardware and laboratories, optimize the teachers' ability model with interdisciplinary characteristics, combine theory and practice to cultivate students' core qualities, ultimately to promote the better popularization of AICE.
\end{abstract}

Keywords: Artificial Intelligence, Education, Elementary and Middle School, Primary Education, Curriculum Education

\section{人工智能课程教育的问题分析及破解之策}

\author{
周丹 $1, \mathrm{a}$ ，弎娜娜 2, b*
}

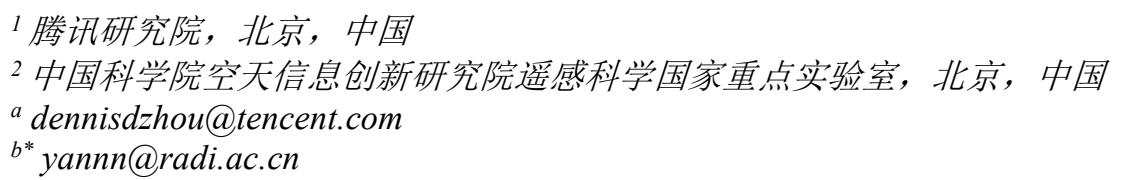

\section{摘要}

中小学人工智能课程教育已在全国各地如火如茶地开展, 但也暴露出缺乏统一教学指导, 部分教师授课能力欠 缺，各地教育资源不均衡等问题。文章通过实地走访、座谈交流等方式，结合当前各地政策及教学实践情况， 从课程标准建立、教师能力发展、学生核心素养培养、因地制宜促进教育公平等方面提出破解之策。建议基于 新课标统一认知, 丰富硬件、实验室等教学实践, 以跨学科为特色优化教师能力模型, 理论与实践结合培养学 生核心素养，最终推动人工智能课程教育更好普及。

关键词: 人工智能，教育，中小学，基础教育，课程教育

\section{1.引言}

人工智能作为新一轮科技革命和产业革命的重 要驱动力量, 正在深刻改变人们的生活、工作和教育 学习方式, 而人工智能人才的培养是其中的关键环节。
世界各国都在积极探索，普及青少年编程，加快发展 人工智能教育 ${ }^{[1]}$ 。美国从 2010 年开始逐步推广，并 于 2018 年启动“美国 K12 人工智能教育行动”，目前 已有一半以上的青少年接受了编程教育; 英国在 2013 年将“计算科学”列为小学阶段必修课，学生从 5 岁开 
始接受编程教育; 澳大利亚将编程融入“数字技术”并 从 5 年级开始列为必修课。

我国非常重视中小学人工智能课程教育的开展, 早在 2017 年, 国务院就印发了《新一代人工智能发 展规划》[2], 明确提出“人工智能成为国际竞争新焦点, 在中小学阶段设置人工智能相关课程, 逐步推广编程 教育”; 2018 年, 《教育信息化 2.0 行动计划》中又提 到“加强学生信息素养培育, 完善课程方案和课程标 准, 充分适应信息时代、智能时代发展需要的人工智 能和编程课程内容”。可见, 中小学人工智能课程教 育的深化研究与推广, 是我国教育发展和智能人才培 养的重要环节。

\section{2. 人工智能课程教育遇到的问题分析}

目前, 中小学人工智能课程教育仍处于起步和探 索阶段。文章通过实地走访、座谈交流等方式, 深入 多地中小学校的实际教学, 梳理出目前我国中小学人 工智能课程教学推广中存在的几个突出问题。

\section{1. 缺乏统一教材和教学指导}

我国 K12 阶段尚未出台统一规范的课程标准, 实 际教学中缺乏统一的教材和指导。迄今为止, 我国出 版的中小学人工智能相关教材已超过 45 本 $^{[3]}$, 尚不 包括未出版的自编教材。资源较为庞杂, 其中, 有国 家版本、也有地方版本, 有企业联合开发版本、也有 高校降维版本, 这在一定程度上造成了地方教学选择 的困惑。以湖北武汉为例, 目前在同步实施开展试点 教学的有 4 个版本之多, 也算是在难以统一标准化背 景下的一种尝试。同时, 一些教材并未遵循教学规律, 缺乏科学的教学指导, 内容设计分层有待商榷; 与教 材相关的教师用书、辅导用书等配套教辅鲜有出版, 使得一线教学难以系统标准化。

人工智能的课程定位模糊 ${ }^{[4]}$, 由于教育管理者和 教师普遍缺乏对人工智能学科的清晰认识, 教学方案 大多沿袭传统创客教育、机器人、纯编程的方案, 对 什么是真正人工智能教学方案并没有形成规范性的 认知和界定; 与人工智能理论教学相关联的教具、实 验室等注重实践的教学方案也尚未统一标准。

\section{2. 部分教师授课能力久缺}

人工智能课程教育的核心问题之一是教授学生 如何通过设计智能机器来模仿人解决实际的问题。目 前, 各地中小学校尚不能保证有专职的人工智能课程 教师, 实际授课常由信息技术或数学等教师兼任, 这 些教师的学历背景大多是师范类院校计算机及其他 专业, 缺乏专业的人工智能知识培训和相关课程开发 能力; 教研活动形式也多局限于理论知识讲解和纯编 程实践, 对跨学科融合、教师发展、学生培养的策略 关注偏少。另外, 部分地区针对人工智能课程的授课 教师缺乏系统性、持续性的能力提升培训, 受各种教
学管理机制和其他因素限制, 导致教师的参培动力也 明显不足, 部分教师授课能力欠缺, 影响实际教学工 作的开展。

\section{3. 各地教育资源投入和政策支持力度不均 衡}

我国已进入教育先行的发展趋势, 教育投资的增 长速度超过了国民经济的增长速度, 以 2019 年为例, 全国 GDP 增速为 $6 \%$, 财政性教育经费的增长速度已 达到 $8.7 \%$; 但各地教育资源和在人工智能教育方面 的投入分配存在严重不均衡的现象，仍以 2019 年为 例, 黑龙江、辽宁、河北等 16 省的人均教育经费远 低于全国平均值，而广东、浙江、上海、北京等地的 该项支出则数倍于全国平均值, 呈现出明显的地区差 异。

同时，各地对人工智能教育的政策支持力度不一, 如浙江、江苏、山东、北京等地早在 2017-2019 年就 陆续发布通知，分别就信息技术纳入新高考、在中小 学普及编程教育、遴选人工智能教育试点区和试点校、 促进人工智能与教育融合发展等方面先行先试。一般 来说, 人均教育经费支出越高, 出台地方性支持政策 就越早越频繁, 人工智能教育的普及推广效果也越好。

\section{3. 人工智能课程教育的破解之策}

基于以上人工智能课程教育中的主要问题分析, 文章从课程标准建立、教师能力发展、学生核心素养 培养、教育资源均衡等方面寻求破解之策。

\section{1. 基于新课标统一认知, 丰富硬件和实验室 教学实践}

2020 年，教育部更新发布了《普通高中信息技 术课程标准》[5], 如表 1 所示, 明确将“人工智能”列 为信息技术的“选择性必修课”, 这其中传递了几点信 息: (1) 人工智能非常重要, 是必修课而不是选修课; （2）人工智能全面融入信息技术课程，是信息技术 课程下的一个分支模块; (3) 人工智能短期内不会独 立成为一门单独的学科。2021 年, 教育部将发布 K9 阶段的信息科技课程标准,建立完善整个 K12 阶段的 包含人工智能在内的信息课标体系, 使得广大中小学 教师教学和教材编写“有据可依”。由此, 各地可以结 合新的统一的课程标准和当地实际水平, 选择已通过 审定教材或联合研发具有当地学校特色的教材。

\section{表 1 高中信息技术课程结构（2020 版）}

\begin{tabular}{|c|l|}
\hline 类别 & \multicolumn{1}{|c|}{ 模块设计 } \\
\hline 必修 & \multicolumn{1}{|c|}{ 模块 1: 数据与计算 } \\
& 模块 2: 信息系统与社会 \\
\hline $\begin{array}{c}\text { 选择性 } \\
\text { 必㫦块 1: 数据与数据 }\end{array}$ & $\begin{array}{l}\text { 模块 4: 人工智能初 } \\
\text { 构 }\end{array}$ \\
\hline
\end{tabular}




\begin{tabular}{|c|l|l|}
\hline & $\begin{array}{l}\text { 模块 2: 网络基础 } \\
\text { 模块 3: 数据管理与 } \\
\text { 分析 }\end{array}$ & $\begin{array}{l}\text { 模块 5: 三维设计与 } \\
\text { 创意 } \\
\text { 模块 6: 开源硬件项 } \\
\text { 目设计 }\end{array}$ \\
\hline 选修 & $\begin{array}{l}\text { 模块 1: 算法初步 } \\
\text { 模块 2: 移动应用设计 }\end{array}$ \\
\hline
\end{tabular}

由于人工智能教学具有较强的学科融合性和动 手实践性, 相关实验室的建设和硬件教具等的配套将 变得日益重要。考虑到教育公平的普惠性和教学的多 样性原则, 建议可以吸引接纳更多的科技公司等社会 力量参与, 在课标体系的指导下分类别细化、分地区 实施、分步骤推广。同时, 人工智能教学还需建立起 相应的学业要求和评价标准, 打通教、学、考、评、 管的闭环, 有效解决目前业界认知不统一、缺乏有效 指导的问题。

\section{2. 以跨学科为特色优化教师能力模型, 政策 扶持落实师资培训}

人工智能的出现, 得益于信息科学、生理、心理 等多种学科之间的互相促进, 因此人工智能人才的培 养, 也必将促进人工智能与其他学科的交叉融合, 成 为教与学发展的重要推动力。图 1 展示出人工智能与 多学科的交叉融合。比如, 人工智能与生物学科融合, 可以让学生从医学成像的视角认知人体的生理结构; 人工智能与语文学科融合, 可以让学生理解机器是如 何生成诗歌的, 体会机器的艺术性与人类的艺术性有 何差异; 人工智能与地理遥感融合, 通过视频结构化 技术, 可以在精细化城市三维模型、城市基础设施健 康诊断等方面有着广泛的用途 ${ }^{[6]}$ 。

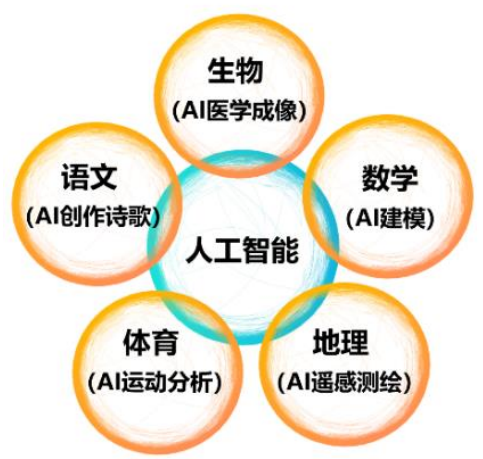

图 1 人工智能与其他学科的交叉融合

人工智能学科具有交叉性强、覆盖面广、更迭速 度快等特点, 因此, 对教师的复合知识体系、重构教 研能力、教学流程再造水平提出了更高的要求。人工 智能教师的能力结构优化模型如图 2 所示, 首先要满 足包括学情分析、教学设计、学法指导和学业评价等 指标在内的信息技术应用能力基本要求; 其次, 基于 不同学科背景教师的能力画像, 鼓励教师发挥自身积 极性和创造性, 将不同学科间的知识以及知识与情境 关联起来, 开展跨学科教学课程设计、组织实施和多 元评价, 形成更多更好的教学实践案例, 有效弥补单
一学科的短板, 丰富多元化多学科融合发展。

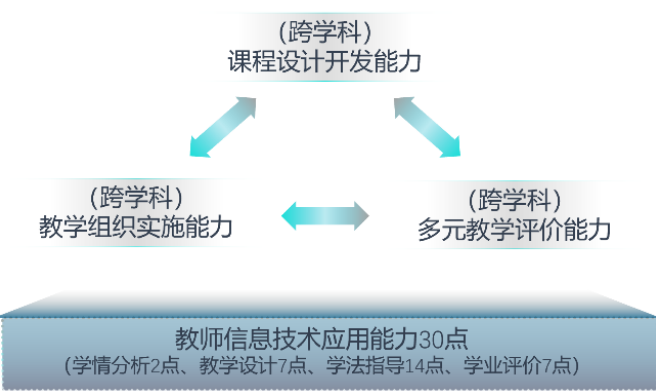

图 2 人工智能学科教师能力结构优化模型

最后，在人工智能教师的培养制度上，建议多方 力量参与, 构建职前职中一体化的师资培训体系, 如 图 3 所示。比如在山东青岛, 教育局通过将人工智能 培训学习与教师的考核晋升等关联, 鼓励教师积极参 加培训并付诸实践, 形成全员学习人工智能的氛围, 提升全市教师的人工智能素养水平。

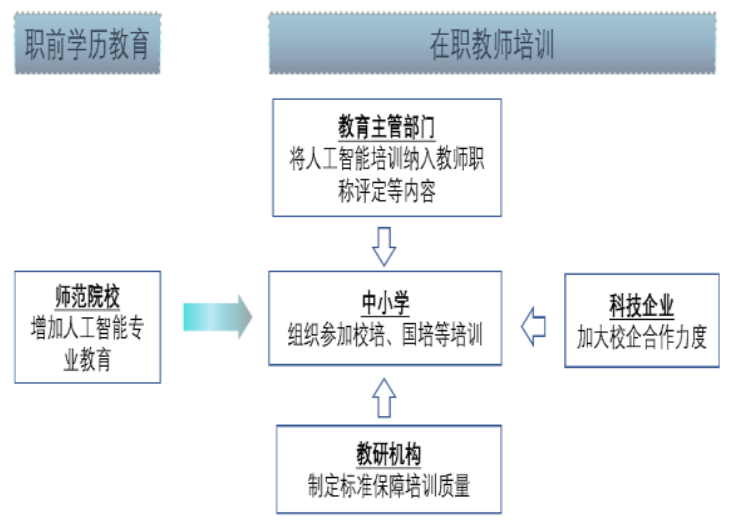

图 3 人工智能学科教师职前职后一体化培训

\section{3. 理论与综合实践相结合, 注重培养学生人 工智能核心素养}

人工智能教育要注意理论与综合实践相结合, 在 《普通高中信息技术课程标准》中对学生的核心能力 素养做了细化要求, 便于对其进行全面的综合素质评 价, 主要包括: (1) 计算思维, 学生能描述人工智能 基本认知, 会利用应用框架搭建简单系统; (2) 数字 化学习与创新思维, 了解人工智能新进展新应用, 适 当运用在学习生活中; (3) 信息意识与信息社会责任, 了解人工智能发展历程, 客观认识对社会生活影响。

动手实践教学分为两个方面, 一方面是人工智能 软件编程实践, 旨在培养提高学生的计算思维, 比如 能够学习认知常用的人工智能算法模型、顺利搭建并 训练模型, 完成人工智能核心知识点的动手实践。另 一方面是人工智能硬件及综合实践，比如搭建智能快 递分拣线、垃圾自动识别系统、老人防跌倒检测关爱 系统等, 旨在培养学生的创新思维和信息意识, 能够 基于特定场景、特定任务完成相应智能硬件的组装与 
连接, 并与人工智能软件算法配合, 重现理论过程或 解决实际问题, 如图 4 所示。

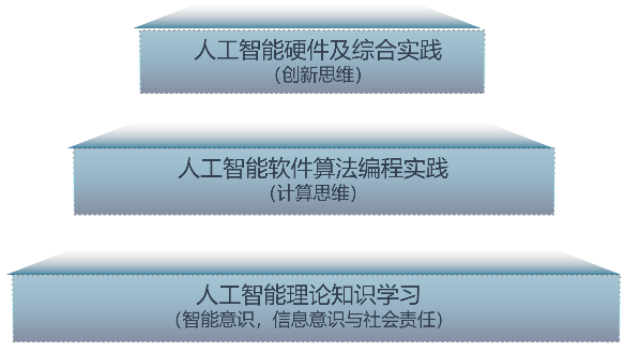

图 4 人工智能理论实践相结合学生素养模型

\section{4. 因地制宜因村施教，促进教育公平}

《教育信息化 2.0 行动计划》中提出, 到 2022 年基本实现“三全两高一大”的发展目标, 教学应用覆 盖全体教师、学习应用覆盖全体适龄学生、数字校园 建设覆盖全体学校, 信息化应用水平和师生信息素养 普遍提高, 建成“互联网+教育”大平台 ${ }^{[7]}$ 。目前, 教育 资源在我国东西部的分布仍很不均衡, 在东部发达地 区早已率先完成该目标, 一些重点中学甚至会配备十 多名专职人工智能教师, 开展多门人工智能细分领域 课程, 如表 2 所示; 而在中西部偏远地区, 教育信息 化硬件配备仍不齐全, 当地学校大部分老师的信息化 教学素养仍有欠缺, 专职人工智能教师配备更是奢望 之谈。

对于东部发达地区的人工智能课程教育, 应该提 供更多丰富的人工智能课程, 为学生提供更多选择的 机会, 瞄准创新、引领的定位, 为全国提供参考标杆, 树立灯塔效应。

\section{表 2 东部某重点中学人工智能课程示例}

\begin{tabular}{|c|c|}
\hline 类别 & 科目/活动 \\
\hline 基础类 & $\begin{array}{r}\text { 人工智能初步、数据与计算、 } \\
\text { 建模与仿真、计算社会学 }\end{array}$ \\
\hline 研究类 & $\begin{array}{c}\text { 人工智能前沿应用、机器人与人工智能、 } \\
\text { 机器视觉与深度学习、自动驾驶、自然语 } \\
\text { 言处理 }\end{array}$ \\
\hline 实践类 & $\begin{array}{c}\text { 项目式学习、科创竞赛、高校衔接、企业 } \\
\text { 实习 }\end{array}$ \\
\hline
\end{tabular}

对于中西部地区, 政府应该吸引鼓励更多企业发 挥社会责任担当, 结合当地实际情况, 组织基础师资 培训, 开展线上线下多种方式教学, 尽可能的促进实 现教育公平。比如在云南, 沧源县教育局与腾讯教育 联手, 通过可持续教师培训、完善课程设置、开展编 程竞赛、组织交流活动等, 加大力度普及推广编程教 育。迄今为止, 刚刚脱贫的沧源县, 编程教育方面已 经实现了“在全县普及中小学编程教育, 从县城直属 小到边境村小全覆盖”。这让偏远地区的孩子们也能 及时接触和学习到高质量的编程课, 有机会缩短与发
达地区的差距。未来, 腾讯将通过“可持续社会价值 创新”的战略升级, 支持更多的教育创新和乡村振兴, 促进中西部的人工智能教育发展, 实现教育公平。

\section{4. 结论}

“谁掌握了人工智能, 谁就把握住了未来!”我 国中小学人工智能的课程教育目前仍处在探索阶段, 短时间内不可能一蹴而就, 需要我们遵循该学科课程 教育的客观规律, 依据相关课程标准, 并鼓励在实践 中不断探索完善, 提升教师的授课能力和学生的核心 素养, 通过政府和企业等社会力量的广泛参与, 解决 教育资源不均衡的问题, 为提升全民数字素养水平共 同努力。

\section{REFERENCES}

[1] Sun, D., Li, Y. (2019) The development status, research hotspots and enlightenment of youth programming education in China and foreign countries: also discuss the implementation strategy of programming education for China in the age of intelligence. J. Journal of Distance Education., 3:47-60.

[2] State council. (2020) Notice of the State Council on the issue of a new generation of artificial intelligence development plans. http://www.gov.cn/zhengce/content/2017-07/20/con tent_5211996.htm.

[3] Wang, D.L., Zhou, D.Q., Wang, Y.R., Yang, X.M. (2021) Review of artificial intelligence teaching materials of primary and secondary schools. J. Modern Educational Technology.,2:19-25.

[4] Lu, Y., Tang, Y.Y, Song, J.C., Yu, S.Q. (2021) Artificial intelligence education in K-12 schools in the intelligent era: strategic positioning and core content domains. J. Distance Education in China.,5:22-31.

[5] Ministry of Education of China. (2020) General High School Information Technology Curriculum Standards. Peoples Education Press.

[6] Dai, X. P. (2020) Moving from digital to intelligent mapping technology requires data drive. http://www.nsfc.gov.cn/publish/portal0/tab446/info 79198.htm.

[7] Ministry of Education of China. (2018) Action Plan on Educational Informatization 2.0 http://www.moe.gov.cn/srcsite/A16/s3342/201804/t 20180425_334188.html. 